\title{
Н.А. Трофимова, В.В. Мамцева
}

\section{ВЕРБАЛЬНАЯ РЕПРЕЗЕНТАЦИЯ ЖЕНСКИХ ЗАПАХОВ ИСКУССТВЕННОГО ПРОИСХОЖДЕНИЯ В НЕМЕЦКОЯЗЫЧНОМ РОМАНТИЧЕСКОМ ДИСКУРСЕ}

\footnotetext{
Рассмотрена проблема описания вербальной репрезентации женских запахов искусственного происхождения в рамках романтического общения. После краткого обзора способов описания запаха в цеелом проводится анализ языкового выражения различных характеристик запаха женщины, выявляются специфические особенности использования единичных лексем для передачи запаховых очущений. В заключении приводится текстовая репрезентация когнитивной модели женской ольфакторности, соединяющая все описанные языковые факты в логически связанный сиенарий и наглядно демонстрирующая объем $u$ внутреннее смысловое содержание исследуемой предметной области.

Ключевые слова: запах женщины, метафора, синестезия, ольфакторная агрессия, одорический, романтический дискурс.
}

Постановка вопроса. Настоящая статья посвящена рассмотрению лингвистической репрезентации феномена «запах», который, будучи первобытным инстинктом, «братом дыхания», проникает в самую глубину, прямо в сердце и выносит категорическое суждение о симпатии и презрении, об отвращении и влечении, о любви и ненависти [1. С. 188]. Особый интерес авторов статьи связан с исследованием роли и средств вербализации запаха в романтическом общении, под которым понимается эмоциональное взаимодействие влюбленных индивидов, «осуществляющих обмен эмотивными вербальными и невербальными знаками» [2. С. 5]. Материалом исследования послужили текстовые фрагменты, отобранные из произведений современной художественной литературы жанра «любовный роман» на немецком языке. В качестве единицы исследования рассматривается выраженная в тексте коммуникативная эмоциональная ситуация, в которой, как известно, восприятие участников общения специфически обострено, а запахи партнера и окружающей среды становятся эмоциональным фоном общения, создают уникальное психофизиологическое состояние любящих, неконтролируемое сознанием. Доминантой ольфакториума в романтическом дискурсе является наполненное образностью описание запаха женщины, избранное предметом рассмотрения в настоящей статье. Основой анализа стала вербальная репрезентация женского запаха искусственного происхождения в контексте романтических отношений с мужчиной, воздействующего на влюбленного партнера на подсознательном уровне и манипулирующего его физиологическими реакциями. 
Проблема описания запаха. Запах - исключительно сложный для описания феномен, поскольку его восприятие очень субъективно, а описание средствами языка представляет собой существенную проблему в связи с отсутствием собственного запахового вокабуляра: «Семантического поля запахов не существует. Понятие запаха включает лишь общие термины для таких субкатегорий, как “зловоние» и “благоухание»»” [3. С. 86]. Иначе говоря, основной способ описания запаха представляет собой его гедонистическую оценку, т.е. деления ольфакторности по принципу приятное / неприятное [4. S. 99]. Взрослый человек, имеющий некоторый ольфакторный опыт, способен вербализовать ассоциативные нюансы гедонистической оценки при помощи сильнооценочных прилагательных unverwechselbar / herrlich / göttlich / wunderbar и под. запах (приятный) или abstoßend / schrecklich / widerlich / unerträglich и под. запах (неприятный). С точки зрения прототипической теории категоризации мы имеем дело с градуальной биполярной категорией ольфакторной перцепции, в основе которой находятся две ядерные лексемы: приятный / неприятный (запах). Все остальные вербальные обозначения запаха (как, например, вышеуказанные прилагательные и им подобные) рассматриваются как элементы этой категории, более или менее отдаленные от прототипических центров [5. S. 186].

Еще одним традиционным способом описания запаха является указание на источник запаха или называние запаха-ориентира по формуле $x$ riecht / duftet / stinkt nach y (der Geruch/Duft / Gestank von y) с небольшими вариациями, при помощи которой мы «нащупываем» точную ассоциацию в памяти для описания нашего обонятельного ощущения. Всего несколько лексем (Geruch, Duft, Gestank u соответствующие глаголы) используются в качестве ядра одорем - словосочетаний, употребляемых при обозначении запаха. Они различаются направлением оценки запаха: der Geruch (riechen) обозначает нейтральный запах, просто констатирует наличие запаха, не концентрируясь на его положительности или отрицательности. Лексемы der Duft (duften) и der Gestank (stinken), одорические антонимы, обозначают положительный (приятный аромат) и отрицательный (неприятный, смрад, вонь) запахи соответственно: der Duft der Rosen, der Duft von Pfefferminz; der Gestank einer Wanze, der Gestank des Friedhofs. Эти лексемы являются удобными эвокационными сигналами, кратко, одним словом воссоздающими в памяти определенный обонятельный образ [6. С. 8]: Zu allem Überfluss wehte aus dem Backhaus der Duft von frischem Brot herüber (Bonn). Интересное замечание в связи с семантикой базового глагола riechen: в немецком языке не фиксируется оппозиция, отражающая восприятие запаха (активное или пассивное) и проявление запаха как свойства (ср. в русском языке: нюхать - обонять - пахнуть), значения восприятия и проявления запаха выражается одним и тем же глаголом riechen [7. С. 6].

Третий способ описания запаха - метафоры, оценивающие и объясняющие ольфакторную реальность. Наиболее репрезентативным классом ольфакторных метафор являются синестезии, интегрирующие чувственные восприятия различных модальностей и достигающие таким образом значи- 
тельной когнитивной интенсивности и коммуникативной плотности изложения / описания положения дел [8. S. 66]: <...> die neue Frau ihres Vaters steht mittlerweile ganz nah bei ihr und strömt einen süßen und bitteren dichten Duft nach Parfum und nach sich selbst aus (Stangl). Очевидно, что прилагательные süß, bitter и dicht употреблены в приведенном примере не в буквальном смысле, здесь налицо метафорический перенос значения из сферы вкуса (süß, bitter) и сферы осязания (dicht) в сферу запаха. С точки зрения гедонистической оценки эти прилагательные репрезентируют скорее домен неприятный (запах): riecht süß, bitter und dicht $=$ riecht schwer $=$ riecht unangenehm, в приведенном контексте эта оценка детерминирована еще и психологическим фактором - индивидуальным неприятием лица, «носящего» описываемый запах.

Синестетические метафоры наполняют описание запаха специфическим содержанием, определяют ситуативно значимые признаки запаха. Включенные в семантическую структуру синестезий описания эмоциональных психофизиологических соощущений положительной или отрицательной направленности передают эмоциональное переживание обонятельного ощущения субъектом восприятия запаха [9. С. 124-125]. Этот факт является доминирующим в настоящем изложении, поскольку именно эмоциональное восприятие определяет выбор обозначений для воспринимаемого в ситуации романтического общения запаха.

Описание запаха женщины в романтическом дискурсе. Из исследований биологов известно, что запах противоположного пола экзистенциально привлекателен, этот аспект восприятия запаха называют сегодня даже шестым чувством, позволяющим неосознанно, только по запаху выбирать партнера. Восприятие запаха настолько важно в ситуациях романтического общения, что для обозначения этого процесса вместо глагола riechen используется метафора atmen, соотносящаяся с первобытным инстинктом, идеей жизни, не требующей никакого «украшения» в виде определений или обстоятельств: $\underline{E r}$ atmete ihren Duft (Berger). Поэтому логично, что описание физиологического воздействия запаха является одной из важнейших тематических областей при создании одорического образа представительниц слабого пола. Даже если создатель художественного произведения просто констатирует факт наличия такого возбуждающего влияния, сознание взрослого читателя, имеющего ольфакторный опыт, рождает представление о возможных последствиях женской запаховой «атаки»: Sie ging an mir vorbei, und ich sah ihr Gesicht nicht, aber ihr Duft entfachte mein Begehren. Bilder der Lust, die ich mit ihr erleben möchte (Paolo). Вторжение запаха духов любимой женщины в личное пространство мужчины делает его одержимым, разжигает его любовную страсть: Ihr Parfüm Jan beschwört_immer ihre unsichtbare Anwesenheit herauf. Ist sie fern, so zieht es mich unwiderstehlich an, ist sie hier, dann erregt es mich wie ein heiliger Zauber (Paolo). В следующем текстовом фрагменте подчеркивается, что искусно подобранная парфюмерия способна усилить влечение мужчины даже в самом преклонном возрасте: Brust und Haare hatte (sie) so stark gesalbt, dass selbst ein Greis noch Feuer fing (Faure). 
Изучение искусственного запаха женщины невозможно представить без обращения к проблеме тела и телесности, так как, рассуждая об эротичности парфюма, мы в первую очередь говорим о запахе тела женщины. Стремление завуалировать естественные запахи, подавить запах тела с помощью искусственных одорантов, сделать его более приятным и привлекательным становится обязательным условием зарождения «горячих» желаний. Так, перед первой близостью для ольфакторного «украшения» тела употребляются запахи распускающихся цветов, выступающие недвусмысленным символом невинности, свежести и прелести возлюбленной: Ehe sie zu ihrem Bräutigam ging, begab sie sich in die Hände ihrer Dienerinnen, die als erstes ihre zarten Glieder mit duftender Salbe aus Jasmin- und Keyata-Blüten einrieben (Paolo). Но и в ситуациях, когда интимный опыт возлюбленной не подлежит сомнению, правильный подбор ароматов способен произвести нужное эмоциональное впечатление на мужчину, завлечь его целой гаммой услаждающих и эротизирующих запахов: Im Sommer parfümieren sich die schönen Damen am Hofe ihre Brüste mit Öl vom Sandelholz, die Haare mit Jasminöl, den Körper mit Rosenwasser. So sind sie bereit für die Liebe (Paolo). Опытные соблазнительницы знают правильное сочетание одорантов для воздействия на партнера: обладающий расслабляющим действием запах сандалового дерева, жасминовое масло, а также розовая вода, вызывающая симпатию с первого взгляда [10. С. 62-74]. Для создания «музыки тела», устранения его естественных запахов и ольфакторной эротизации атмосферы общения парфюмируются гениталии и нижнее белье [11. S. 180].

Анализ особенностей вербальной репрезентации воздействия женского парфюма позволяет выделить значимость отдельных лексических единиц в качестве средств передачи обонятельных ощущений.

Ценность духов женщины заключается в том, что они являются одним из действенных средств управления впечатлением партнера. Неоднократно под воздействием эмоций прослеживаются мотивы, в которых искусственный запах может подавлять своей агрессивностью соперника и привлекать партнера. Следовательно, наименования, отражающие провокационный характер запаха женщины, выделяются в отдельную категорию запахов-агрессоров.

Агрессивный характер запаха возлюбленной проявляется в том, что он не имеет границ, в состоянии влюбленности партнер не может перестать его обонять. Подобное принудительное восприятие запаха женщины формирует в сознании влюбленного мужчины образ живого существа, детерминирующего его психофизиологическое состояние. Ведущим средством репрезентации такого одорического образа становится метафорически переосмысленная предикатная лексика обонятельного восприятия женских духов. Так, шлейф парфюма женщины из объекта восприятия превращается в равноправного участника коммуникации, захватывающего власть над влюбленным мужчиной. Изменения в эмоциональной сфере, стимулируемые духами женщины, подтверждаются, например, метафорическим фразеосочетанием den Atem verschlagen: Ihr intensives, für eine Frau ihres Alters viel zu schweres Parfüm verschlug ihm fast den Atem $<\ldots>$ (Emme). 
В группу глаголов со значением психического воздействия можно также отнести метафорическое переосмысление глаголов verfolgen, überfallen. В примерах ниже показано, что парфюм любимой женщины оказывает агрессивное влияние на мужчину: преследует его, воздействует на его поведение и настроение, лишает возможности сопротивляться физиологическому влечению: Der Duft ihres Parfüms überfiel ihn. Seine Hand glitt hinüber. Er berührte ihre Schenkel. Sie öffneten sich, und seine Lust auf Lyssi verdrängte für Sekunden um ihn her alle Farben und Geräusche (Berger).

Запах женщины оказывает воздействие как невидимый «диверсант», скрыто, ползком проникающий на «территорию» мужчины и совершающий там действия, подрывающие его моральные устои: Ein Hauch ihres ... Parfums kroch in seine Nase und der junge Mann ertappte sich dabei, sich vorzustellen, wie es wäre, sie anzufassen und zu küssen (Vertacnik).

Немаловажную роль в формировании агрессивного воздействия парфюма женщины играют метафорические переносы значений производных форм глаголов - причастий betörend, betäubend, berauscht, которые репрезентируют запах как чарующее и пьянящее приворотное зелье для партнеpa: Sie löste sich nur langsam, genoss sie seine Berührung? Er sog tief ihr Parfum ein, der Duft war frisch, blumig und dennoch betörend (Buttler); Sie verwendete das gleich schwere, betäubende Parfüm wie damals, streichelte über Widos Hüften, fühlte seine Wärme (Schneeweiß); Wenn ich sie umarme und sie mir die Lippen öffnet, bin ich berauscht vom Wein ihres Parfüms, das ich trinke (Paolo).

Таким образом, глаголы verfolgen, überfallen, betören, betäuben, berauschen и их производные, не имеющие семантического компонента «способ восприятия запаха», метафорически передают действие специфического женского «химического оружия», убивающего мужчину наповал или оглушающего, одурманивающего его.

Коко Шанель называла духи аксессуаром, дающим знать о появлении женщины и продолжающим напоминать о ней, когда она ушла. Эта важная способность невидимой прекрасной «вуали» выражает индивидуальность женщины, ее характер, является частью внешнего эффекта, произведенного женщиной: Als die Haustür mit einem schwungvollen Knall ins Schloss fiel, lag der Duft ihres neuen Parfüms noch in der Luft (Artmeier); Das Parfüm der Freundin schwappte in schweren Wellen zu Doreen herüber. Es überschrie den leichten Duft nach Kaffeebohnen, der in der Luft gelegen hatte, bevor sie gekommen war. Представленные примеры наглядно демонстрируют, что в процесс метафоризации запаха вовлекаются глаголы со значением движения, перемещения, способа распространения парфюма возлюбленной: in der Luft liegen, herüberschwappen. Запах, будучи явлением неосязаемым, не имеет свойств, выражаемых этими глаголами, однако их употребление в описании запаха женщины характеризует его как нечто материальное, окружающее влюбленного мужчину со всех сторон, заполняющее пространство вокруг него или набегающее на него волнами. Запах сравнивается и с некоторым объектом, способным висеть (hängen) в воздухе, запол- 
нять пространство вокруг: Und die Frau trug ein dezentes Parfüm, dessen herbe Wildfruchtnote eine kurze Weile an der Bar hängen blieb, während sie selber bereits auf der andern Seite bediente (Lascaux).

Иначе говоря, особенностью описания искусственного запаха возлюбленной является использование запахово-эмоциональных синестетических (синэстемических по С.Ф. Воронину [12]) способов описания восприятия женской ольфакторности, построенных на совмещении тактильных и запаховых впечатлений. Синестетический перенос в область обоняния осуществляется при помощи глаголов бытийно-посессивной семантики [13. C. 34-36] tragen или auflegen, представляющих парфюм женщины неким невидимым покрывалом, являющимся обязательным элементом ее внешнего образа: Als sie erschien, lächelte sie wie ein Engel von Botticelli, und das Parfüm, das sie trug, hatte sie aus einem himmlischen Versandkatalog (Lascalux); Sie hatte wieder dieses Parfüm aufgelegt, das ihn so sehr an den Sommer erinnert hatte und an das Leben (Mader).

Еще одной синестетической моделью при описании восприятия запаха является сравнение парфюма возлюбленной с некой жидкой субстанцией, впитываемой (einsaugen, aufsaugen) окружающими: Er sog tief ihr Parfum ein, der Duft war frisch, blumig und dennoch betörend (Buttler). Духи уподобляются и хорошему вину, от которого слегка кружится голова: Wenn ich sie umarme und sie mir die Lippen öfnet, bin ich berauscht vom Wein ihres Parfüms, das ich trinke (Paolo). В запахе духов можно даже плыть как в водном потоке: <...> sie stellt sich vor, ein Mann zu sein, diese Frau beim Tanzen in den Armen zu halten, durch den süßen, schweren Duft zu schwimmen wie durch die süßen schweren Klänge, all das auf sich wirken zu lassen (Stangl).

Символическая составляющая запаха женщины во многом определяется ее оценочным восприятием. Для оценочной концептуализации внешних и внутренних качеств женщины используются оценочные прилагательные, характеризующие саму женщину, ее поведение, образ жизни. Важно отметить, что оценка отдельного свойства парфюма оказывает влияние на оценку женщины в целом. Так, в следующем высказывании прилагательное auserlesen применительно к духам женщины выражает признак изысканности ее образа: Meine Freundin, nimm dieses Parfüm an, es enthält als Symbol den Duft meines Lebens. Deinem auserlesenen Parfüm opfere ich ein anderes, so wie man Bacchus Wein opfert, sein eigenes Elixier (Paolo).

Значительную роль в описательной характеристике запаха женщины играет интенсивность, стойкость парфюма, его концентрация в воздухе. Так, например, для того чтобы подчеркнуть элегантность, изысканность женщины, указывают на небольшое количество нанесенного парфюма (ein paar Tröpfchen des... Parfüms), поскольку даже капелька аромата способна создать яркий образ, уникальную «музыку» на коже. Дополнительная оценка атрибутами paradiesisch придает всей модели субъективную характеристику: Dann sprühte sie ein paar Tröpfchen des paradiesischen Parfüms auf ihre Finger und verrieb es hinter den Ohren (Lascaux). Но стоит хоть немного превысить комфортную для окружающих концентрацию духов (ein 
im leichten Übermaß aufgetragenes Parfüm), восприятие запаха перемещается в сферу агрессивного, лишающего возможности дышать, и появляются враждебно «атакующие» метафоры восприятия (in die Nase stechen), как, например, в следующем примере: Ihre Kleidung eine Mischung zwischen Eleganz und Gothic (...). Dazu stach ein im leichten Übermaß aufgetragenes Parfüm in die Nase, herb und aufregend, aber atemberaubend im wörtlichen Sinne (Lascalux).

В ситуациях интимного общения парфюм возлюбленной является прочной «обонятельной основой» отношений, создает атмосферу близости. В этом факте подтверждается известное мнение Ж.Ж. Руссо о том, что чувство берет свое начало в обонянии, что запах и страсть неразделимы. Чувственный аромат заставляет сердце мужчины биться чаще, использовать при описании запаха атрибуты в превосходной степени: Das Parfüm, das du immer bei dir trägst, oh Aphrodite, ist nicht nur das sinnlichste und verheißungsvollste für die Liebe, es verwandelt auch in Schönheit was wir sehen, so als ob es alle Dinge und alle Lebewesen zu glücklicher Schönheit machte (Paolo).

Но искусственный запах женщины в романтическом дискурсе может наделяться гедонистической оценкой просто как «приятный запах», и тогда он превращается в средство внешней презентации гендерной идентичности женщины, для которой важно произвести первое впечатление, придать значимость своей личности, своим успехам. Запах в этом случае становится декоратором внешности и усилителем воздействия на мужчину. Для описания «приятности» запаха достаточно употребления прилагательного gut, которое в сочетании с интенсификатором (например, verdammt или himmlisch) создает нужное впечатление: Sie trug einen schwarzen Rock, eine etwas tiefer ausgeschnittene, aber doch elegante weiße Bluse und eine schwarze Perlenkette. Zoff hätte zu gerne gewusst, welches Parfum sie aufgetragen hatte. Jedenfalls roch es verdammt gut (Vertacnik).

Очевидно, что минимальная структура языкового выражения ольфакторной оценки искусственного запаха женщины не обязательно репрезентируется прилагательными, относящимися к области обоняния. Социальная ольфакторная идентичность женщины выражается, например, прилагательным teuer, актуализирующим в запаховом контексте идею престижности, материального благополучия, возможности получения роскошного удовольствия, имеющего признак классовости: Kurze Röckchen und dünne Blusen. Hohe Schuhe, die die Wadenmuskulatur strafften. Erstklassig geschminkte Gesichter, rosa glänzende Lippen und teure Düfte. Die Damen wollten gefallen. Sie wollten die Aufmerksamkeit erwachsener Männer auf sich ziehen. Sie wollten verführt werden. Sie forderten es heraus. Bezaubernd und kokett (Puhlfürst).

Заключение. На основе представленного выше взгляда в мир запаха можно построить когнитивную модель женской ольфакторности в романтическом дискурсе как вывод-обобщение, который позволяет упорядочить описанные языковые факты, соединить их в единый, логически связанный сценарий [14. С. 408]. Эта модель объединяет семантические и функцио- 
нальные особенности языковых средств, используемых для обозначения женского запаха - в первую очередь метонимических и метафорических (особенно синестетических) переносов, дополненных положительнооценочными прилагательными. Приведенная ниже текстовая репрезентация максимально полной когнитивной модели «запах женщины» позволяет наглядно продемонстрировать объем и внутреннее смысловое содержание исследуемой предметной области.

Итак, запах женщины есть ее невидимая одежда или покрывающая ее вуаль, обязательный элемент декорирования внешности. Для романтического свидания «надевается» аромат, создающий впечатление невинности, укутывающий «красу и юность тела объятьем тайны». Для интимной встречи женщина «украшает» себя чувственным ароматом, взывающим к глубинным инстинктам мужчины, обещающим негу и сладострастие. Запах дорогих духов репрезентирует статус и материальное благополучие женщины, характеризует ее изысканный вкус, в романтическом общении он становится символом элитного, статусного удовольствия.

Влюбленному мужчине запах женщины заменяет жизненно необходимый воздух, он дышит им и при его отсутствии просто задыхается. Эта летучая красота заполняет все окружающее пространство, становится ольфакторным автографом женщины, остается надолго после ее ухода.

В ситуациях страстной увлеченности женщиной ее запах представляется агрессором, он неодолим, присутствует повсюду, преследует тайно и явно, пронизывает влюбленного мужчину, проникает в его сознание, владеет его воспоминаниями, рушит его моральные устои, манипулирует его биологической сутью.

Влюбленный мужчина впитывает, пьет запах любимой женщины как дурманящий напиток, как пьянящее вино, запах воспринимается как специфически действующий наркотик, кружащий голову и «привязывающий» сознание сильно и надолго.

Проведенный анализ показывает убедительность запаха женщины, который сильнее слов, очевидности, чувства и воли (П. Зюскинд). Исследование романтической ольфакторной топики позволяет не только проникнуть в многообразный вербальный мир сенсориума человека, но глубже постичь удивительное эйфорическое пограничное состояние сознания, которое мы называем любовью, решить парадоксальную ситуацию нахождения человека между субъективной эмоциональностью и рациональностью коллективного языка.

\section{Литература}

1. Трофимова Н.А. Роль одорических репрезентаций в процессе смыслопорождения (на материале романа П. Зюскинда «Парфюмер») // Homo Loquens: Актуальные вопросы лингвистики и методики преподавания иностранных языков. СПб., 2012. Вып. 4. C. $188-197$.

2. Ренц Т.Г. Романтическое общение в коммуникативно-семиотическом аспекте : дис. ... д-ра филол. наук. Волгоград, 2011. 196 с. 
3. Риндисбахер Х.Д. От запаха к слову: Моделирование значений в романе Патрика Зюскинда «Парфюмер» // Ароматы и запахи в культуре / пер. Я. Токаревой // Новое лит. обозрение. 2000. № 43. С. 86-101.

4. Vroon P., Amerongen A. van, Vrias H. de. Psychologie der Düfte. Zürich : Kreuz, 1996. $278 \mathrm{~S}$.

5. Holz P. Cognition, olfaction and linguistic creativity // Speaking of colours and odors by M. Plümacher and P. Holz (Ed.). Amsterdam/Philadelphia : J. Benjamin Publishing Group, 2007. P. 185-202.

6. Куликова Н.А. Одорический код в художественном тексте: лингвоэвокационное исследование (на материале художественной прозы А.П. Чехова) : дис. ... канд. филол. наук. Курск, 2010. 247 с.

7. Павлова Н.С. Лексика с семой «запах» в языке, речи и тексте : автореф. дис. ... канд. филол. наук. Екатеринбург, 2006. 20 с.

8. Holz P. Die Sprache des Parfüms. Eine empirische Untersuchung zur Grammatik, Metaphorik und Poetizität des Parfümwerbetextes. Hamburg : Verlag Dr. Kovač, 2005. $308 \mathrm{~s}$.

9. Молодкина Ю.Н. Синестетическая метафора запаха: корпусное исследование : дис. ... канд. филол. наук. Горно-Алтайск, 2010. 196 с.

10. Вайнштейн О.Б. Историческая ароматика: одеколон и пачули // Ароматы и запахи в культуре / сост. О.Б. Вайнштейн. Кн. 2. М., 2010. С. 440-466.

11. Ebberfeld I. Botenstoffe der Liebe: über das innige Verhältnis von Geruch und Sexualität. Münster : LIT Verlag, 2005. 252 S.

12. Воронин С.Ф. Основы фоносемантики. M. : URSS, 2009. 248 с.

13. Гейко E.B. Смысловой тип пропозиции и его манифестация в современной русской речи: На материале высказываний, содержащих информацию о запахах : дис. ... канд. филол. наук. Омск, 1999. 191 с.

14. Лакофф Дж., Джонсон М. Метафоры, которыми мы живем // Теория метафоры. M., 1990. C. 397-416.

\section{Источники иллюстративного материала}

1. Artmeier H. Drachenfrau. Meßkirch, 2011.

2. Buttler M. Herzraub. Meßkirch, 2011.

3. Berger R.W. Laura. Föritz, 2004.

4. Berger R.W. Spitzenrausch. Föritz, 2006.

5. Faure P. Magie der Düfte: eine Kulturgeschichte der Wohlgerüche von den Pharaonen zu den Römern. M. ; Zürich: Artemis-Verl., 1991.

6. Graf E. Leopardenjagd. Meßkirch, 2011.

7. Emme P. Pastetenlust. Meßkirch, 2011.

8. Lascaux P. Wursthimmel. Meßkirch, 2011.

9. Paolo $R$. Auf der Suche nach den verlorenen Düften: eine aromatische Kulturgeschichte [aus den Italienischen von Heli Tortora]. M. : Hugendubel, 1995. $300 \mathrm{~S}$.

10. Puhlfürst C. Leichenstarre. Meßkirch, 2011.

11. Schneeweiß H. Das, worin Vergehen waltet. Oberhausen, 1999.

12. Schröder A. Mordsliebe. Meßkirch, 2011.

Verbal Representation of Female Artificial Smells in German-Language Romantic Discourse

Vestnik Tomskogo gosudarstvennogo universiteta. Filologiya - Tomsk State University Journal of Philology. 2019. 58. 71-81. DOI: 10.17223/19986645/58/5

Nella A. Trofimova, Higher School of Economics (Saint Petersburg, Russian Federation), Pushkin Leningrad State University (Saint Petersburg, Russian Federation). E-mail: nelart@mail.ru 
Vera V. Mamtseva, Military University of the Ministry of Defence of the Russian Federation (Moscow, Russian Federation) E-mail: rusosipova@gmail.com

Keywords: woman's smell, metaphor, synaesthesia, olfactory aggression, odorous, discourse of intimate communication.

The present article tackles the question of smell semantics and semiotics in the context of intimate communication of sexes. The authors analyze the linguistic representation of different characteristics of a woman's artificial smell and identify specific features of single lexemes' use for the transmission of olfactory sensations. The analysis shows that the main ways of describing smell are:

1) hedonic odor assessment: evaluation by the "pleasant / unpleasant" criterion,

2) naming the smell-reference (riecht nach / Geruch von),

3) metaphorical transfer, especially to other sensory spheres (synesthesia), which distinguishes situationally significant signs of odor.

These language devices are used with approximately equal frequency and depend on individual olfactory preferences and on being included in a certain context. This fact is especially relevant for the study of smell representation in the intimate, often irrational reality of lovers' communication.

When describing smell in the romantic discourse - one of lovers' communication - the main thematic area is the nomination of a physiological impact on a partner who feels the existential necessity of perceiving the smell of the beloved woman and desire for physical affinity. This effect is verbalized by metaphors which represent women's smell as an omnipresent peremptory aggressor pursuing the man in love, penetrating into his consciousness, owning his memories, destroying his moral foundations, manipulating his biological essence.

Smell is also often perceived as a poisonous substance that stupefies, deafens and intoxicates, emphasizing the insidious nature of the female smell, which acts on the invisible "front" secretly as a hidden saboteur.

An important means of describing female artificial smell in romantic discourse is sensoryemotional synesthesia that represents smell as a thirst quencher or a veil enveloping the beloved person with an invisible cloud. The smell of a beloved woman is delicious and sweet, gentle and sensual; its assessment takes the entire positive scale from "good" to "divine".

The symbolic component of a woman's smell is largely determined by her axiological perception, represented by evaluative adjectives that characterize the behavior, the way of life of a woman, and evaluate her as a whole. Adjectives are, in addition, a means of verbal presentation of a woman's gender identity with an emphasis on the importance of selfpresentation, "adornment" with pleasant smells.

In conclusion, the authors give a textual representation of the cognitive model of the female artificial smell, which connects all linguistic facts described above into a single logically connected scenario. This model demonstrates the scope and the internal semantic content of the subject area.

\section{References}

1. Trofimova, N.A. (2012) Rol' odoricheskikh reprezentatsiy v protsesse smysloporozhdeniya (na materiale romana P. Zyuskinda "Parfyumer") [The role of odoric representations in the process of meaning generation (based on P. Suskind's Perfume)]. Homo Loquens: Aktual'nye voprosy lingvistiki i metodiki prepodavaniya inostrannykh yazykov 4. pp. 188-197.

2. Rents, T.G. (2011) Romanticheskoe obshchenie v kommunikativno-semioticheskom aspekte [Romantic communication in the communicative-semiotic aspect]. Philology Dr. Diss. Volgograd.

3. Rindisbakher, Kh.D. (2000) Ot zapakha k slovu: Modelirovanie znacheniy v romane Patrika Zyuskinda "Parfyumer" [From smell to word: Modeling values in Patrick Suskind's 
Perfume]. Translated from English by Ya. Tokareva. Novoe lit. obozrenie - New Literary Observer. 43. pp. 86-101.

4. Vroon, P., Amerongen, A. Van \& de Vrias, H. (1996) Psychologie der Düfte. Zürich: Kreuz.

5. Holz, P. (2007) Cognition, olfaction and linguistic creativity. In: Plümacher, M. \& Holz, P. (eds) Speaking of colours and odors. Amsterdam/Philadelphia: J. Benjamin Publishing Group.

6. Kulikova, N.A. (2010) Odoricheskiy kod $v$ khudozhestvennom tekste: lingvoevokatsionnoe issledovanie (na materiale khudozhestvennoy prozy A.P. Chekhova) [The odor code in the literary text: a language evoked study (on the material of the prose by A.P. Chekhov)]. Philology Cand. Diss. Kursk.

7. Pavlova, N.S. (2006) Leksika s semoy "zapakh" v yazyke, rechi i tekste [Vocabulary with the seme "smell" in language, speech and text]. Abstract of Philology Cand. Diss. Yekaterinburg.

8. Holz, P. (2005) Die Sprache des Parfüms. Eine empirische Untersuchung zur Grammatik, Metaphorik und Poetizität des Parfümwerbetextes. Hamburg: Verlag Dr. Kovač.

9. Molodkina, Yu.N. (2010) Sinesteticheskaya metafora zapakha: korpusnoe issledovanie [Synesthetic metaphor of smell]. Philology Cand. Diss. Gorno-Altaysk.

10. Vaynshteyn, O.B. (2010) Istoricheskaya aromatika: odekolon i pachuli [Historical aromatics: cologne and patchouli]. In: Vaynshteyn, O.B. (ed.) Aromaty $i$ zapakhi $v$ kul'ture [Aromas and smells in culture]. Book 2. Moscow: NLO.

11. Ebberfeld, I. (2005) Botenstoffe der Liebe: über das innige Verhältnis von Geruch und Sexualität. Münster: LIT Verlag.

12. Voronin, S.F. (2009) Osnovy fonosemantiki [Basics of phonosemantics]. Moscow: URSS.

13. Geyko, E.V. (1999) Smyslovoy tip propozitsii $i$ ego manifestatsiya v sovremennoy russkoy rechi: Na materiale vyskazyvaniy, soderzhashchikh informatsiyu o zapakhakh [The semantic type of the proposition and its manifestation in modern Russian speech: On the material of statements containing information about smells]. Philology Cand. Diss. Omsk.

14. Lakoff, G. \& Johnson, M. (1990) Metafory, kotorymi my zhivem [Metaphors we live by]. In: Arutyunova, N.D. \& Zhurinskaya, M.A. (eds) Teoriya metafory [Theory of metaphors]. Moscow: Progress.

\section{Sources}

1. Artmeier, H. (2011) Drachenfrau. Meßkirch.

2. Buttler, M. (2011) Herzraub. Meßkirch.

3. Berger, R.W. (2004) Laura. Föritz.

4. Berger, R.W. (2006) Spitzenrausch. Föritz.

5. Faure, P. (1991) Magie der Düfte: eine Kulturgeschichte der Wohlgerüche von den Pharaonen zu den Römern. Münich; Zürich: Artemis-Verl.

6. Graf, E. (2011) Leopardenjagd. Meßkirch.

7. Emme, P. (2011) Pastetenlust. Meßkirch.

8. Lascaux, P. (2011) Wursthimmel. Meßkirch.

9. Paolo, R. (1995) Auf der Suche nach den verlorenen Düften: eine aromatische Kulturgeschichte [aus den Italienischen von Heli Tortora]. Moscow: Hugendubel.

10. Puhlfürst, C. (2011) Leichenstarre. Meßkirch.

11. Schneeweiß, H. (1999) Das, worin Vergehen waltet. Oberhausen.

12. Schröder, A. (2011) Mordsliebe. Meßkirch. 